\title{
Angiomatoid giant cellular blue nevus of vaginal wall associated with pregnancy
}

\author{
Mubarak M Al-Shraim
}

\begin{abstract}
Background: Blue nevi that arise from the Müllerian tract are rare melanocytic lesions. Several histopathologic variants of cellular blue nevi have been described. The angiomatoid variant is characterized by a vascular component, and is considered to be a rare variant. Few studies have explored the influence of pregnancy on melanocytic lesions.
\end{abstract}

Case: A 29-year-old woman was presented with a pigmented vaginal lesion that increased gradually during pregnancy. A full term gynecologic examination showed a tumor mass protruding into the vaginal canal. The mass was resected during cesarean-section under the clinical impression of vaginal hemangioma.

Result: Gross examination revealed a cystic mass measuring $6.0 \times 4.3 \times 3.5 \mathrm{~cm}$, which was filled with dark friable material. Histologically, the mass showed a subepithelial cellular proliferation of heavily pigmented dendritic melanocytes with prominent vascular stroma. Cytologic pleomorphism, junctional activity, atypical mitosis, and necrosis were not found. The proliferation was immunoreactive for HMB-45, S-100 and melan-A, and nonimmunoreactive for CD34, smooth muscle actin, and AE1/AE3. The MIB-1 proliferative index was less than 1\%. The patient had a postoperative course without complication.

Conclusions: Angiomatoid giant cellular blue nevus arising from the vagina during pregnancy is extremely rare. The low proliferative index and absence of cytologic pleomorphism, or necrosis, supports a benign biological behavior. Clinical follow-up showed no evidence of recurrence at one year after the resection of the mass.

Keywords: Cellular blue nevus vagina, pregnancy, melanocytes

\section{Introduction}

Blue nevi are rare benign pigmented lesions that are derived from dermal melanocytes. They may develop on anatomical regions such as hands or feet, and, less commonly, on the head, neck, trunk and buttocks [1]. Their occurrence at extra-cutaneous sites including meninges, orbit, conjunctiva, maxillary sinus, oral mucosa, spermatic cord, prostate, lymph nodes, uterine cervix, and vagina are less reported [2].

The classification of blue nevi is complex, with biological behavior being benign, borderline, or malignant [3]. Only a few cases of giant cellular blue nevus (greater than $5 \mathrm{~cm}$ ) have been reported $[4,5]$. The angiomatoid cellular blue nevus is a variant of blue nevus that is rarely reported in the literature [6]. Herein, we describe

Correspondence: malshraim@yahoo.com

Department of Pathology, College of Medicine, King Khalid University, Saudi Arabia

C Biomed Central

(c) 2011 Al-Shraim; licensee BioMed Central Ltd. This is an Open Access article distributed under the terms of the Creative Commons Attribution License (http://creativecommons.org/licenses/by/2.0), which permits unrestricted use, distribution, and reproduction in any medium, provided the original work is properly cited. an unusual case of angiomatoid giant cellular blue nevus that arises from the vagina of a young woman during pregnancy, and present the ultrasonographic, gross, microscopic, and immunohistochemical findings.

\section{Clinical case}

A 29-year-old woman was presented for routine antenatal care, and was found to have a small pigmented lesion in the vagina that increased gradually in size during pregnancy. Gynecologic examination showed a bluish soft lesion on the anterior vaginal wall. A pelvic ultrasound was carried out on the $17^{\text {th }}$ week of pregnancy, and showed a $1.9 \times 0.9 \mathrm{~cm}$ oval hypoechoic bilobed area overlaying introitus (Figure 1). This mass had increased three-fold in size by $37^{\text {th }}$ week of pregnancy, forming a protrusion, which occupied most of the vaginal canal. The clinical impression at this stage was vaginal hemangioma; therefore the patient was selected clinically for 


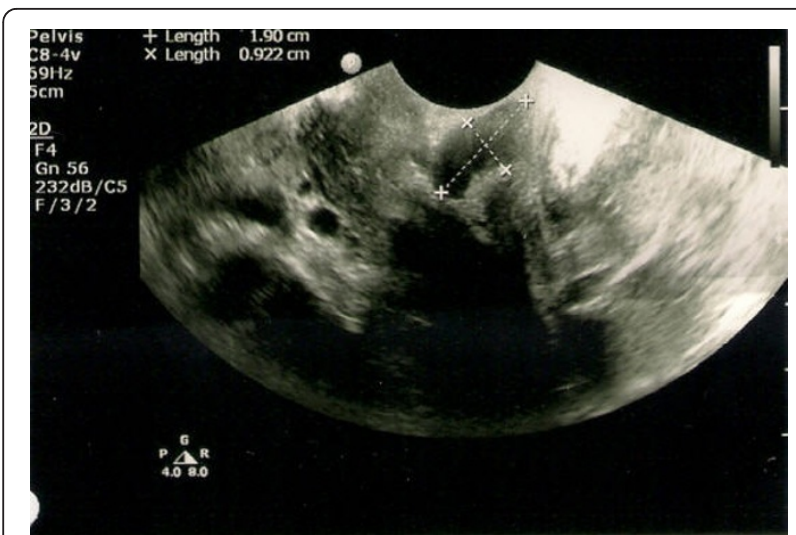

Figure 1 Pelvic ultrasound at the $17^{\text {th }}$ week of pregnancy. There was $1.9 \times 0.9 \mathrm{~cm}$ oval hypoechoic bilobed area overlaying introitus.

cesarean section due to the risk of bleeding. Preoperative laboratory investigations revealed a hemoglobin level of $12.6 \mathrm{~g} / \mathrm{dL}$, a white cell count of $12.1 \times 10^{3} / \mu \mathrm{L}$, and platelet levels of $193 \times 10^{9} / \mathrm{L}$ in the patient. The renal and liver functions were normal. However, the mass was resected during cesarean section, and the patient had a postoperative course without complication. Gross examination showed a cystic mass measuring $6.0 \times 4.3 \times 3.5 \mathrm{~cm}$. The outer surface had focal areas of dark pigmentation (Figure 2). Serial cuts revealed central cystic changes filled with dark friable material. The entire specimen was submitted for histologic evaluation. Microscopic examination revealed a subepithelial cellular proliferation of heavily pigmented dendritic melanocytes that were arranged predominantly in fascicles, and epithelioid nests dissected through the vaginal wall. These were surrounded by collagen fibers, and a prominent vascular stroma associated with frequent melanophages (Figure 3). However, no cytologic pleomorphism, atypical mitosis, or necrosis was found.

There was no melanocytic junctional activity. The histology of the central cyst of the mass lesion revealed blood filled nonendothelial lined pseudovascular spaces that were lined by the lesional cells (in a manner analogous to an angiomatoid melanoma or aneurysmal benign fibrous histiocytoma) (Figure 4) Immunohistochemical analysis of the proliferation using the streptavidin-biotin immunohistochemical technique revealed that the tumor cells were positive for HMB-45, S-100 and melan-A, but negative for estrogen receptor, progesterone receptor, CD34, smooth muscle actin, and AE1/ AE3. The MIB-1 proliferative index was less than $1 \%$. CD31 and factor VIII immunohistochemical stains showed the presence of a prominent small-sized vascular network within the melanocytic proliferation (Figure 5). Clinical follow-up showed no evidence of recurrence at one year after the resection of the mass.

\section{Discussion}

Blue nevi are distinct dendritic melanocytic proliferations that may arise in the skin [3] or Müllerian tract [2]. However, the origin of blue nevi in the Müllerian tract has been subject to controversy. Some authors [7] have proposed that these lesions may originate from melanocytic precursors that migrate towards the epithelium during embryogenesis. Other investigators have suggested that these lesions may result from the transformation of the stromal Schwann cells into melanocytes [2]. A possible source of these lesions in the vaginal wall is aberrantly migrated melanocytes. Nigogosyan et al. [8] recorded three cases in 100 autopsies that had dendritic cells located in the basal layer of the vaginal squamous epithelium. However, melanocytes were not recognized within the vaginal subepithelial stroma despite extensive sampling and utilization of the special stain, Fontana-Masson. This observation may indicate that a small proportion of women have ectopic melanocytes in the vagina, which may act as precursors for vaginal blue nevi and malignant melanomas.

Blue nevi have a wide spectrum of morphological variants. The common blue nevus and cellular blue nevus
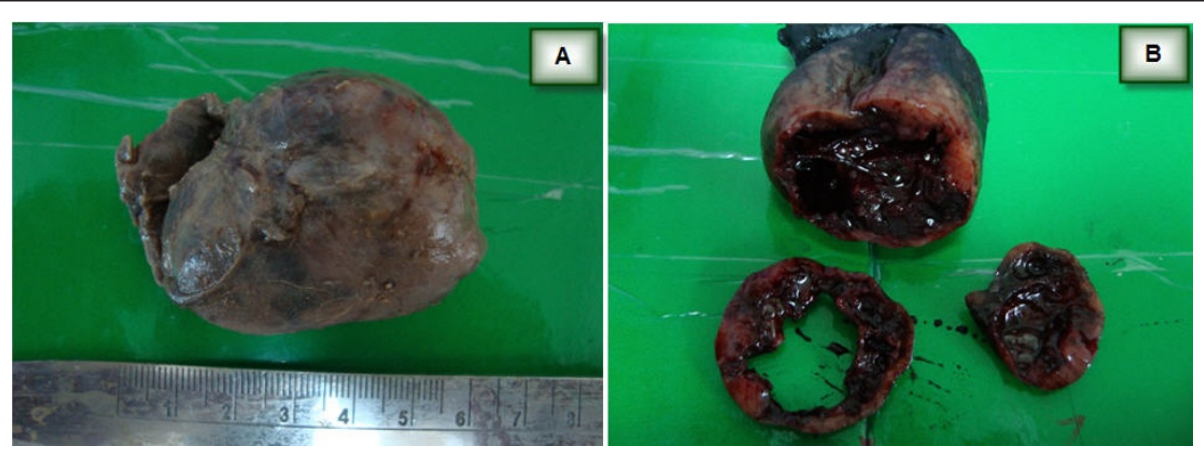

Figure 2 Gross photograph. (A) The tumor mass measuring $6.0 \times 4.3 \times 3.5 \mathrm{~cm}$ with the focal hyperpigmented external surface. (B) A cross section showing the central cystic change filled with dark friable material. 


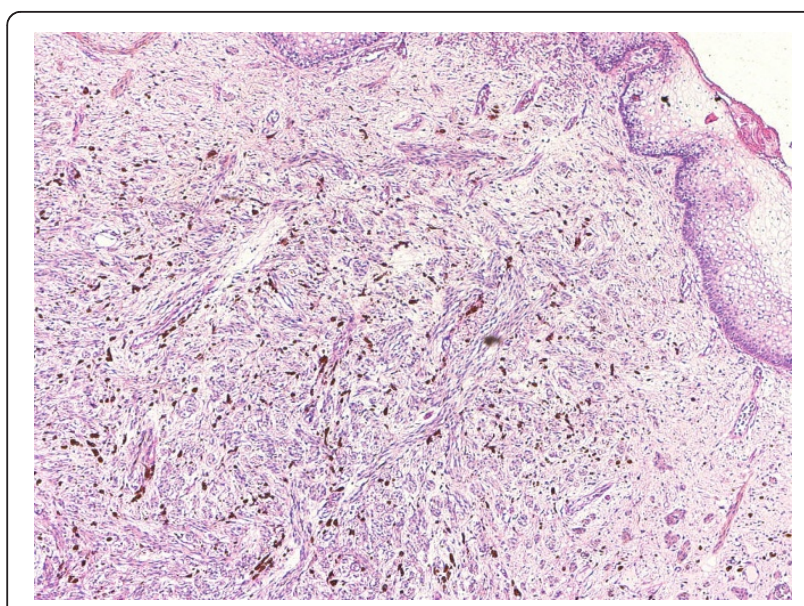

Figure 3 Photomicrograph of the vaginal mass. There is a subepithelial proliferation of spindle cells, accompanied by melanophages (original magnification, $\times 40$, hematoxylin and eosin stain)

are the most frequent types [3]. Other morphologic types include (i) the atypical cellular blue nevus [9], (ii) the desmoplastic cellular blue nevus [10], (iii) the CD34-poistive cellular blue nevus [11], (iv) the epithelioid blue nevus [12], (v) the compound blue nevus [12], (vi) the amelanotic blue nevus [3], (vii) the congential pauci-melanotic cellular blue nevus [13], (viii) the sclerosing mucinous blue nevus [14], (ix) the cellular blue nevus with schwannian differentiation [3], and $(x)$ the angiomatoid cellular blue nevus [6].

The angiomatoid variant is characterized by a vascular component and is described as an extremely rare variant [6].

The presence of a rich vascular component was described as a distinct variant of other tumors, including

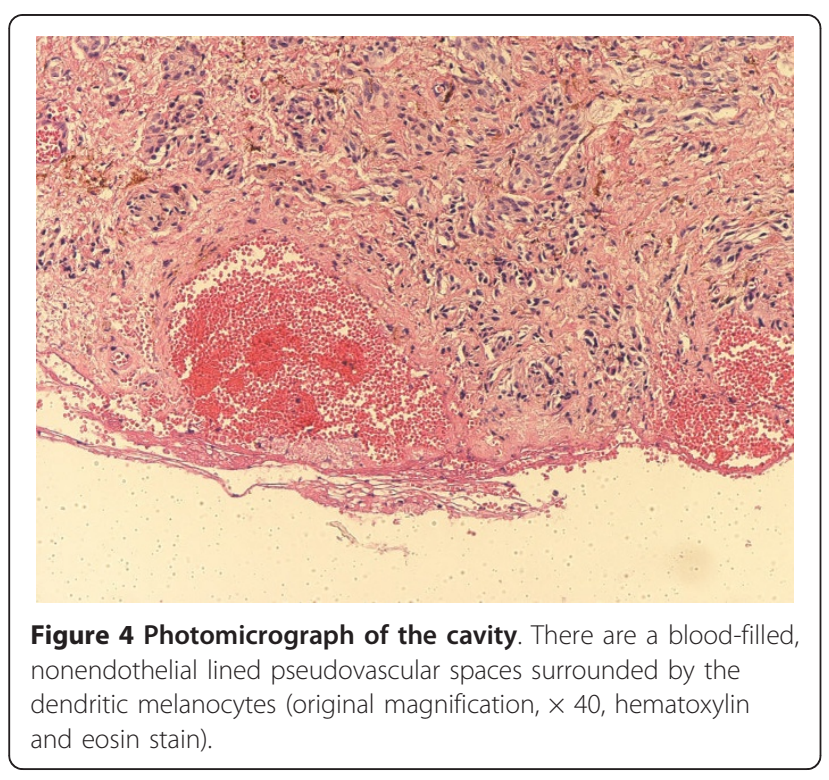

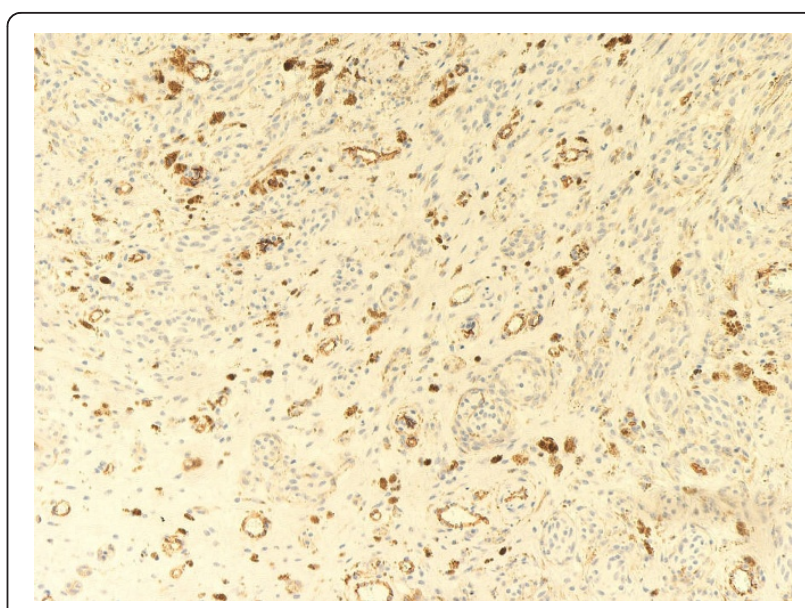

Figure 5 CD31 immunohistochemical stain. There are numerous small-sized vessels within the stroma of the cellular blue nevus.

melanocytic and non-melanocytic lesions. The angiomatoid melanoma is a rare morphologic variant [15]. Angiomatoid dermatofibroma, angiolipoma, and glomangioma, are distinct morphologic variants for nonmelanocytic tumors [16].

The occurrence of a cellular blue nevus in the vagina is extremely rare and, to the author's knowledge, only three cases have been published in the literature [2]. Giant cellular blue nevus (GCBN) has been described in extra-genital sites, such as the chest wall [5]. However, GCBN of the vagina has not been described previously.

Few studies have explored the influence of pregnancy on melanocytic lesions [17] or their size during pregnancy. The cause of enlargement of the melanocytic nevi during pregnancy is subject to controversy. Some authors [17] have proposed that these lesions may be related to the hormonal influence of gestation, although the immunohistochemical studies for the estrogen and progesterone receptors were negative. The increase in the size of the cellular blue nevus in the present case is more likely related to an increased vasculature within the mass lesion, as shown by the immunoreactivity of the prominent vascular network for CD31 and factor VIII immunohistochemical stains. This increase in the vascular component may provide a clinical impression of hemangioma. Furthermore, the presence of central cystic degeneration that was full of hemorrhagic material (Figure 2) may be another contributory factor to the increase in size of this mass during pregnancy.

\section{Conclusion}

The angiomatoid giant cellular blue nevus of the vagina is extremely rare, and may clinically mimic hemangioma. The low proliferative index as shown by MIB-1 immunohistochemical marker and the absence of nuclear pleomorphism, or necrosis indicated benign 
histological features. This observation was supported by the absence of any recurrence at the clinical follow up after one year.

\section{Consent}

Written informed consent was obtained from the patient for publication of this case report and any accompanying images. A copy of the written consent is available for review by the Editor-in-Chief of this journal.

\section{Abbreviations}

\section{GCBN: Giant cellular blue nevus}

\section{Acknowledgements}

The author is grateful to the administrative staff at the College of Medicine, King Khalid University, and Abha Private Hospital (APH), for their support. My thanks are also extended to Dr. Omaima from the Department of Obstetrics \& Gynecology (APH) and Dr. G. Almas Begum from the Department of Radiology (APH), whose help enabled me to review this case. I convey my special thanks to all histopathology technologists including Mr. Alsayed Shahine, Ms. Rahmah, Mr. Ahmed Alhasan, Mr. Ghazi Bargi, Mrs. Shehnaz Khan, and Mr. Saeed Al-Qhtani.

\section{Authors' contributions}

The author prepared, read and approved the final manuscript

\section{Competing interests}

The authors declare that they have no competing interests.

Received: 7 January 2011 Accepted: 8 April 2011 Published: 8 April 2011

\section{References}

1. Crowson AN, Mihm MC, Magro CM: The Melanocytic Proliferation: A Comprehensive Textbook of Pigmented Lesions. New York: Wiley-Liss; 1 2001, 97-120.

2. Craddock KJ, Bandarchi B, Khalifa MA: Blue nevi of the Mullerian tract: case series and review of the literature. J Low Genit Tract Dis 2007, 11:284-89.

3. Ferrara G, Soyer HP, Malvehy J, Piccolo D, Puig S, Sopena J, Zalaudek I, Argenziano G: The many faces of blue nevus: a clinicopathologic study. J Cutan Pathol 2007, 34:543-51.

4. Al-Qattan MM, Bad MS: Cutaneous blue nevi: classification and malignant degeneration. Can J Plast Surg 1994, 2:130-32.

5. Hoos A, Berho M, Blumencranz PW, Brady MS: Giant cellular blue nevus of the anterior chest wall mimicking metastatic melanoma to the breast: a case report. J Surg Oncol 2000, 74:278-81.

6. Urso C, Tinacci G, Urso C, Tinacci G: Angiomatoid cellular blue nevus: a variant of blue nevus with an angioma-like appearance. J Cutan Pathol 2005, 32:385-87.

7. Patel DS, Bhagavan BS: Blue nevus of the uterine cervix. Hum Pathol 1985, 16:79-86.

8. Nigogosyan G, Delapava S, Pickren JW: Melanoblasts in vaginal mucosa, origin for primary malignant melanoma. Cancer 1964, 17:912-13.

9. Avidor I, Kessler E: 'Atypical' blue nevus - a benign variant of cellular blue nevus: Presentation of three cases. Dermatologica 1977, 154:39-44.

10. Michal M, Kerekes Z, Kinkor Z, Ondrias F, Pizinger K: Desmoplastic cellular blue nevi. Am J Dermatopathol 1995, 17:230-35.

11. Smith K, Germain M, Williams J, Skelton H: CD34-positive cellular blue nevi. J Cutan Pathol 2001, 28:145-50.

12. Carney JA, Ferreiro JA: The epithelioid blue nevus: A multicentric familial tumor with important associations, including cardiac myxoma and psammomatous melanotic schwannoma. Am J Surg Pathol 1996, 20:259-72.

13. Busam KJ, Lohmann CM: Congenital pauci-melanotic cellular blue nevus. J Cutan Pathol 2004, 31:312-17.

14. Rongioletti $F$, Innocenzi D: Sclerosing 'mucinous' blue naevus. $\mathrm{Br}$ J Dermatol 2003, 148:1250-52.
15. Adler MJ, Beckstead J, White CR Jr: Angiomatoid melanoma: a case of metastatic melanoma mimicking a vascular malignancy. Am J Dermatopathol 1997, 19:606-09.

16. Rosai J: Rosai and Ackerman's Surgical Pathology.Edited by: Juan Rosai. New York: Mosby, Elsevier; , 9 2004:2:2237.

17. Lee HJ, Ha SJ, Lee SJ, Kim JW: Melanocytic nevus with pregnancy-related changes in size accompanied by apoptosis of nevus cells: a case report. J Am Acad Dermatol 2000, 42:936-38.

doi:10.1186/1746-1596-6-32

Cite this article as: Al-Shraim: Angiomatoid giant cellular blue nevus of vaginal wall associated with pregnancy. Diagnostic Pathology 2011 6:32.

\section{Submit your next manuscript to BioMed Central and take full advantage of:}

- Convenient online submission

- Thorough peer review

- No space constraints or color figure charges

- Immediate publication on acceptance

- Inclusion in PubMed, CAS, Scopus and Google Scholar

- Research which is freely available for redistribution
C Biomed Central 